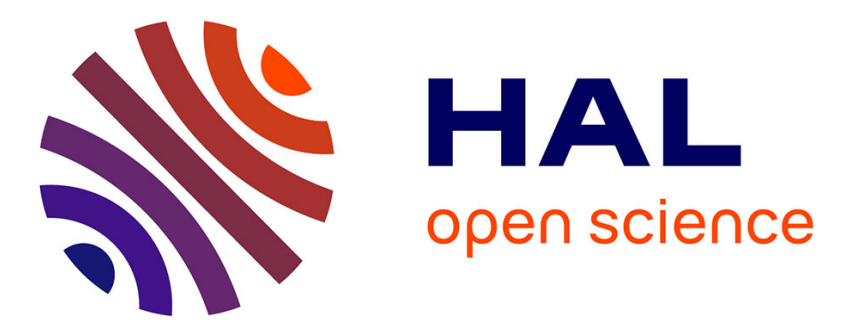

\title{
Site-Selective Arylation of Naphthalenes: a Key Entry towards Extended Fluorenones and Phenanthridinones
}

Benjamin Large, Nicolas Gigant, Delphine Joseph, Gilles Clavier, Damien Prim

\section{- To cite this version:}

Benjamin Large, Nicolas Gigant, Delphine Joseph, Gilles Clavier, Damien Prim. Site-Selective Arylation of Naphthalenes: a Key Entry towards Extended Fluorenones and Phenanthridinones. European Journal of Organic Chemistry, 2019, 2019 (8), pp.1835-1841. 10.1002/ejoc.201900067 · hal-02363527

\section{HAL Id: hal-02363527 \\ https://hal.science/hal-02363527}

Submitted on 14 Nov 2019

HAL is a multi-disciplinary open access archive for the deposit and dissemination of scientific research documents, whether they are published or not. The documents may come from teaching and research institutions in France or abroad, or from public or private research centers.
L'archive ouverte pluridisciplinaire HAL, est destinée au dépôt et à la diffusion de documents scientifiques de niveau recherche, publiés ou non, émanant des établissements d'enseignement et de recherche français ou étrangers, des laboratoires publics ou privés. 


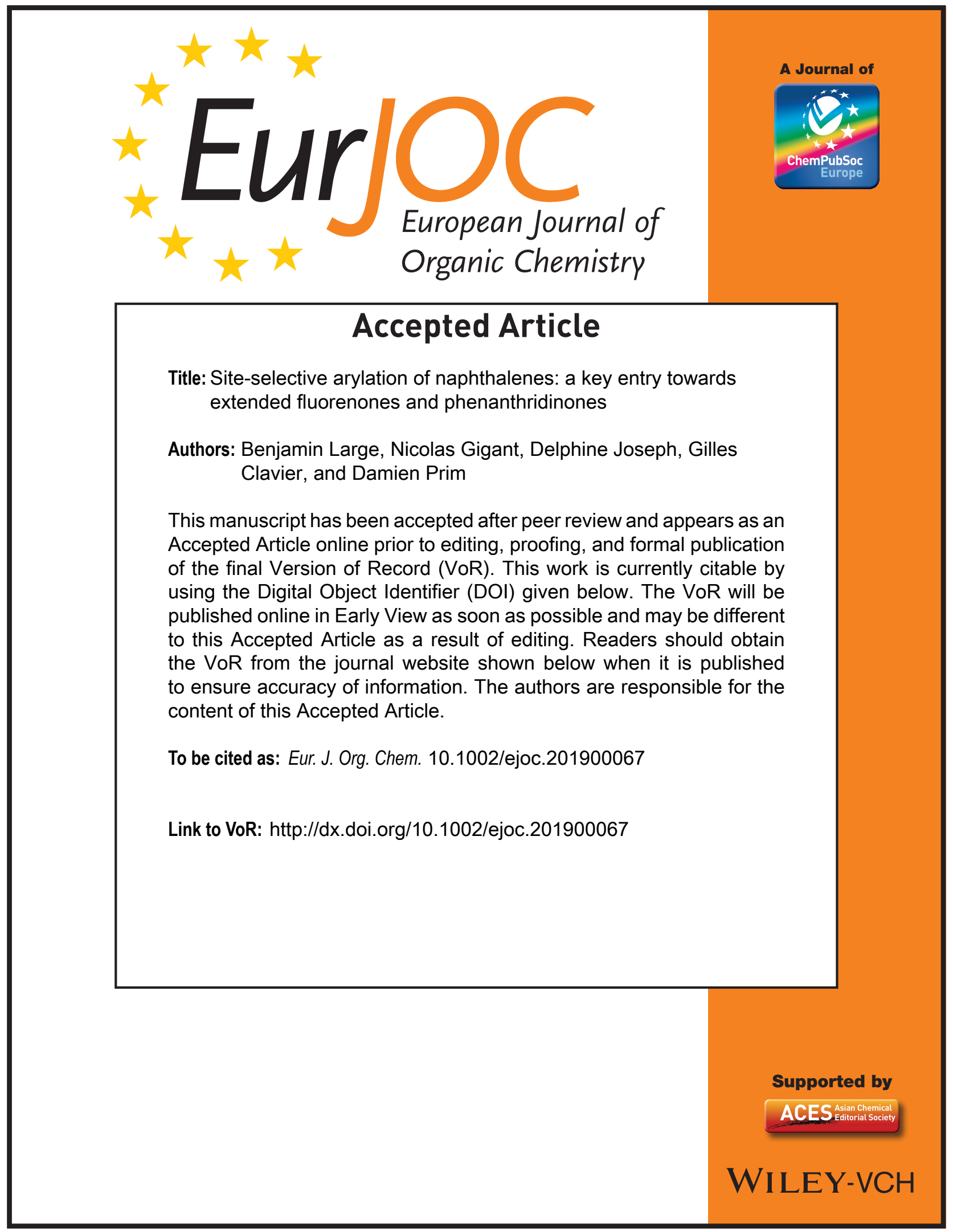




\title{
Site-selective arylation of naphthalenes: a key entry towards extended fluorenones and phenanthridinones
}

\author{
Benjamin Large, ${ }^{[a]}$ Nicolas Gigant, ${ }^{[b]}$ Delphine Joseph, ${ }^{*[b]}$ Gilles Clavier, ${ }^{[c]}$ and Damien Prim ${ }^{\star[a]}$
}

\begin{abstract}
The development of an oriented arylation process dedicated to the naphthalene core is presented. Our approach is based on dual role of $\mathrm{N}$-tosyl carboxamides acting jointly as a directing group in a first $\mathrm{C}-\mathrm{H}$ arylation step and as a "CO" or "CO$\mathrm{NH}^{\prime}$ fragment precursor in a further construction step of naphthalene-based fluorenone or phenanthridinone derivatives. The presence of the directing group in position 1 and 2 of the naphthalene platform allowed selective arylations in position 2 and 3 respectively. Our study represents a first synthetic and general entry of $\mathrm{C}-\mathrm{H}$ arylation at naphthalene platforms towards the preparation of extended fluorenones as well as benzo-fused phenanthridinones. Further, the $\mathrm{C}-\mathrm{H}$ arylation and cyclisation sequence represents a useful way to the preparation of novel extended tetra- and pentacyclic fluorenones bearing both electron donating as well as electron withdrawing groups in various substitution patterns. Additionally, both the regioselectivity and the reaction paths of the cyclization leading to the fluorenone architectures was studied by DFT calculations which fully complement experimental observations.
\end{abstract}

\section{Introduction}

Naphthalene, as the smallest elemental polycyclic arene, is a pivotal building block for the elaboration of more complex polycyclic architectures. The substitution pattern of naphthalene is a key element for the development of a wide range of organic compounds exhibiting privileged $2 \mathrm{D}$ or $3 \mathrm{D}$ shapes with unique properties. Such polycyclic derivatives are particularly widespread in advanced organic materials and natural products. ${ }^{[1]}$ Harnessing their peculiar topology requires the siteselective installation of substituents at the naphthalene platform. Among the modulable positions, the substitution controlled in positions 1 and 2 has received continuing attention notably for the design of chiral catalytic systems based on a binaphthyl core. $^{[2]}$ Indeed, the twisted or helical shape but also the properties of these naphthalene-based angular architectures can

[a] Prof. Dr. D. Prim, B. Large

ILV, UVSQ, CNRS, Université Paris-Saclay, 78035 Versailles,

France

E-mail: damien.prim@uvsq.fr

https://orcid.org/0000-0003-3363-8089

[b] Prof. Dr. D. Joseph, Dr. N. Gigant

BioCIS, Université Paris-Sud, CNRS, Université Paris-Saclay, F-

92296 Châtenay-Malabry, France

E-mail: delphine.joseph@u-psud.fr

https://www.biocis.u-psud.fr/?-JOSEPH-PRIM-Delphine-

[c] Dr. G. Clavier

PPSM, CNRS, ENS Paris-Saclay, Université Paris-Saclay, 94235

Cachan, France

https://orcid.org/0000-0001-7175-7236

Supporting information for this article is given via a link at the end of the document.((Please delete this text if not appropriate)) be modulated by extending of the naphthalene core with fused cycles on these two positions. ${ }^{[1,3]}$ In contrast, extension towards linear molecules is obtained from positions 2 and 3 of the naphthalene unit and, acenes, lignans, prodans, or benzofluorenes and their related analogues are representative congeners. ${ }^{[4]}$

In this context, (poly)functionalised naphthalenes remain challenging targets of general and ongoing interest. Strategies towards the oriented functionalisation of naphthalene units, especially in positions 1,2 and/or 3, has become a major issue over the last decade. The two most common ways are to construct the naphthalene core from prefunctionalised subunits or to install substituents on the naphthalene platform.

Although appealing methodologies have been developed to build up substituted naphthalenes, ${ }^{[5]}$ this approach may require a substantial experimental work as a prerequisite in case of highly substituted precursors. In contrast, the installation of substituents can be realized on the naphthalene unit using classical cross-coupling reactions, starting from naphthol or bromonaphthalene derivatives or more directly using $\mathrm{C}-\mathrm{H}$ activation. Chelation-assisted $\mathrm{C}-\mathrm{H}$ activation has become a powerful and accurate method for regioselective introduction of diversity on aromatic substrates mainly within the benzene series. Despite tremendous recent advances in the development of $\mathrm{C}-\mathrm{H}$ functionalization in the benzene series, naphthalenes remains far less investigated appearing as an occasional or additional example for scope enlargement. ${ }^{[6]}$ Even though siteselective direct arylation in position 1 of naphthalene is depicted in absence of orienting groups, it remains focused on introduction of benzene derivatives only. ${ }^{[7]}$

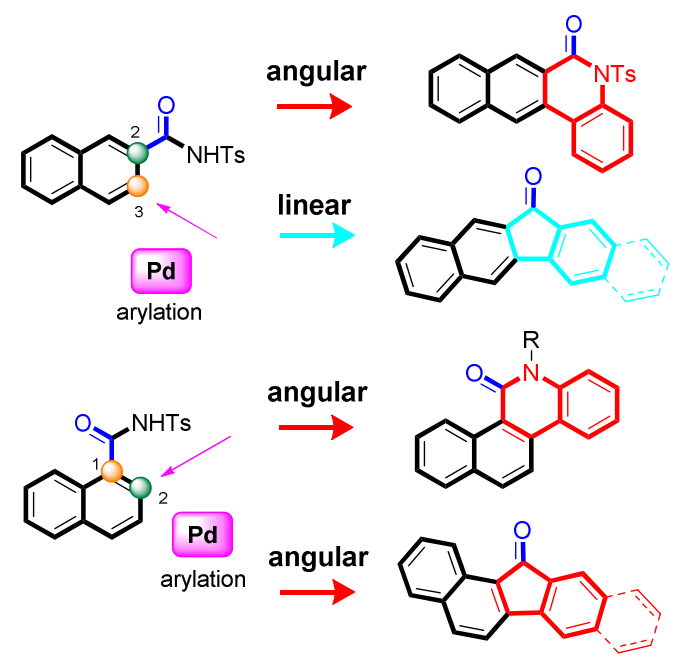

Figure 1. Outcomes of the $\mathrm{C}-\mathrm{H}$ arylation and ring construction sequence starting from naphthalene. 
Advantageously, the latter (i) is easily available from carboxylic acid, (ii) serves as transformable directing group towards molecular diversity, (iii) is compatible with a wide range of functionalisation processes such as arylation, alkenylation/annulation, alkoxylation or chlorination reactions in the benzene series, (v) can be used in combination with various metals including $\mathrm{Pd}, \mathrm{Rh} / \mathrm{Cu}, \mathrm{Ru}$, (iv) appears efficient under smooth reaction conditions. ${ }^{[8]}$

Herein, we disclose a selective $\mathrm{C}-\mathrm{H}$ functionalization of the naphthalene core using $\mathrm{N}$-tosylcarboxamide as directing group. $\mathrm{Pd}$-catalysed arylation reactions have been investigated leading to 1,2- and 2,3-disubstituted naphthalenes and further to linear and angular extended (tetra- and pentacyclic) fluorenones as well as angular benzo-fused phenanthridinones (figure 1). Our strategy provides a complementary route to unreported members of both families. ${ }^{[8 b, 9]}$

\section{Results and Discussion}

We first started to investigate the $\mathrm{C}-\mathrm{H}$ arylation of naphthalenes 1 and 2. Recently, Fabis investigated the arylation reaction using $\mathrm{N}$-tosylcarboxamide as directing group in benzene series. ${ }^{\left[{ }^{8 b]}\right.}$ $\mathrm{Pd}(\mathrm{OAc})_{2}$ and $\mathrm{AgOAc}$ proved to be very efficient as the catalytic combination giving the best ratio of mono- vs di-arylated products and allowing the site-selective installation of a $p$ methoxyphenyl group in a high $70 \%$ yield as an example. We thus preliminarily applied the same catalytic conditions to napththalene $\mathbf{1}$ and $p$-iodoanisole. For this particular polycondensed aromatic substrate, the seminal Fabis conditions afforded a poor conversion leading to a 0.2:1 ratio between the expected arylated product $\mathbf{3 a}$ and the starting material $\mathbf{1}$ (Table 1 , entry 1). Interestingly, the ortho-selectivity of the arylation was retained and only compound 3a was obtained. Albeit optimal on benzene derivatives, these conditions remained less efficient when applied to the more reluctant naphthalene substrate even by increasing catalytic loadings. These first results prompted us to explore new catalytic combinations dedicated to the peculiar naphthalene platform. Selective arylation of naphthalene 1, took place at position 3 at $130{ }^{\circ} \mathrm{C}$ in $\mathrm{AcOH}$ (entry 2) albeit in poor yield (19\%). The use of additives such as $\mathrm{AgSbF}_{6}, \mathrm{Ag}_{2} \mathrm{CO}_{3}$ or $\mathrm{Cu}(\mathrm{OAc})_{2}$ did not improve the conversion or did not avoid the degradation of the starting material. Solvents, concentration, respective amounts of reactants and catalyst loading have also been tested (for full details see ESI). Combination of $\mathrm{Ag}_{2} \mathrm{O}$ (1 eq) and $\mathrm{K}_{2} \mathrm{CO}_{3}(4 \mathrm{eq})$ revealed the most efficient to the $\mathrm{C}-\mathrm{H}$ arylation, target $3 a$ being isolated in $55 \%$ yield (entry 3 ).

Control experiments ran successively without $\mathrm{Ag}_{2} \mathrm{O}$ and $\mathrm{K}_{2} \mathrm{CO}_{3}$ (entries 4 and 5) confirmed the mandatory use of $\mathrm{Ag}_{2} \mathrm{O}$ and $\mathrm{K}_{2} \mathrm{CO}_{3}$ to ensure increasing conversion of the starting material. If an increase of the amount of $\mathrm{Ag}_{2} \mathrm{O}$ only slightly modified the $3 / 1$ ratio, optimal catalytic combination was obtained by using $\mathrm{Ag}_{2} \mathrm{O}$ (1 eq), $\mathrm{K}_{2} \mathrm{CO}_{3}(4 \mathrm{eq})$ and $10 \% \mathrm{Pd}(\mathrm{OAc})_{2}$ in the presence of $2 \mathrm{eq}$ of iodoanisole for 24 hours. Under these conditions, the conversion (25:1) was excellent and naphthalene 3a was isolated in $83 \%$ yield (entry 6 ). Attempts to reduce the amount of
$\mathrm{Pd}(\mathrm{OAc})_{2}$ to $5 \%$ afforded the expected arylated product $3 \mathrm{a}$ albeit in lesser extend (entry 7 ).

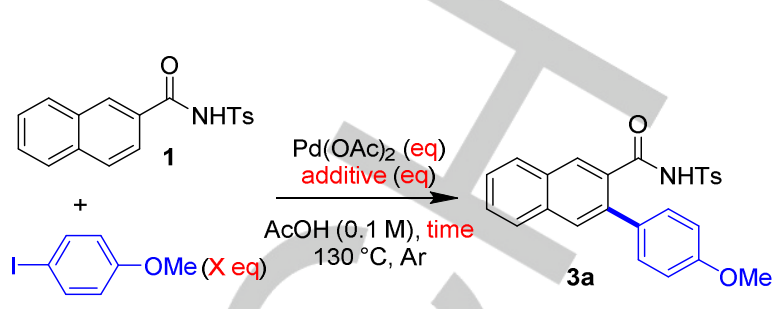

Table 1. Screening conditions for the Pd-catalysed $\mathrm{C}-\mathrm{H}$ arylation of naphthalene $\mathbf{1}$ (full details in ESI

\begin{tabular}{|c|c|c|c|c|c|c|}
\hline Entry & $X(e q)$ & $\begin{array}{l}\text { Pd } \\
\text { (eq) }\end{array}$ & $\begin{array}{c}\text { Additive } \\
\text { (eq) }\end{array}$ & Time & $\begin{array}{c}\text { Ratio }^{[a]} \\
3 a: 1\end{array}$ & $\begin{array}{c}\text { Isolated } \\
\text { Yield }\end{array}$ \\
\hline 1 & 2 & 0 & $\begin{array}{c}\mathrm{AgOAc} \\
(2)^{[8 b]}\end{array}$ & $24 \mathrm{~h}$ & $0.7: 1$ & nd \\
\hline 2 & 1.2 & 0.2 & I & $17 \mathrm{~h}$ & nd & $19 \%$ \\
\hline & 1.2 & 0.2 & $\begin{array}{l}\mathrm{Ag}_{2} \mathrm{O}(1) \\
\mathrm{K}_{2} \mathrm{CO}_{3}(4)\end{array}$ & $22 \mathrm{~h}$ & $3.5: 1$ & $55 \%$ \\
\hline 4 & 1.2 & 0.2 & $\mathrm{Ag}_{2} \mathrm{O}(1)$ & $18 \mathrm{~h}$ & $0.4: 1$ & \\
\hline 5 & 1.2 & 0.2 & $\mathrm{~K}_{2} \mathrm{CO}_{3}(4)$ & $22 \mathrm{~h}$ & $0.5: 1$ & \\
\hline 6 & 2 & 0.1 & $\begin{array}{l}\mathrm{Ag}_{2} \mathrm{O}(1) \\
\mathrm{K}_{2} \mathrm{CO}_{3}(4)\end{array}$ & $24 h$ & $25: 1$ & $83 \%$ \\
\hline 7 & 2 & 0.05 & $\begin{array}{l}\mathrm{Ag}_{2} \mathrm{O}(1), \\
\mathrm{K}_{2} \mathrm{CO}_{3}(4)\end{array}$ & $24 \mathrm{~h}$ & $0.7: 1$ & \\
\hline
\end{tabular}

[a] Determined by NMR. [b] Degradation. nd: not determined

With these conditions in hand, we examined the installation of diversely functionalised iodoarenes in position 3 of naphthalene 1. As shown in scheme 1, iodoarenes bearing electron-donating groups were readily coupled in yields ranging from $58 \%$ to $83 \%$ yields. The use of electron-withdrawing groups $\left(\mathrm{CF}_{3}, \mathrm{~F}, \mathrm{NO}_{2}\right)$ gave modest results. If meta- and para-substituted iodoarenes were efficiently used, the arylation reaction remained reluctant to ortho-substituted substrates hampered by deleterious steric interactions. Installation of a thiophene residue occurred in 15\% yield plausibly due to the well-known sensitivity of thiophenes substrates to acidic conditions. ${ }^{[10]}$ Under our conditions, the $\mathrm{C}-\mathrm{H}$ arylation process proved fully selective. Indeed, only 3-arylated products were observed. Interestingly, a naphthyl group can also be installed selectively at naphthalene $\mathbf{1}$ in $65 \%$ yield. Noteworthy, bisarylation products (in both positions 3 and 1 of the naphthalene platform) were never observed during the process even using larger amounts of the iodoarene, the catalytic system and for prolonged reaction times. 

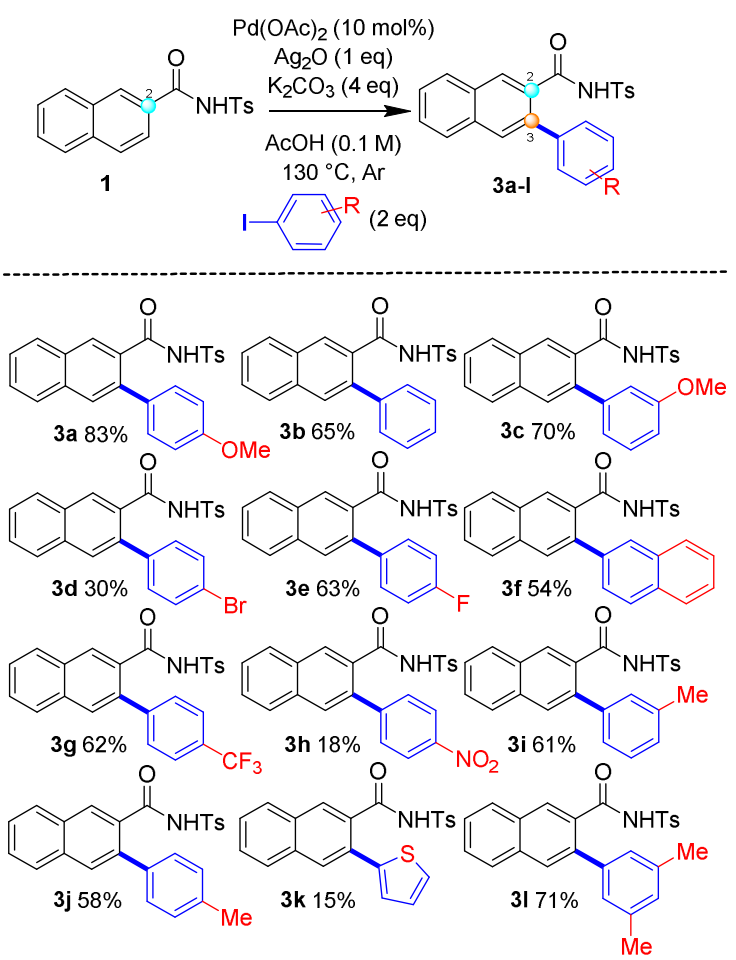

Scheme 1. Synthesis of 3-aryl- $N$-tosylnaphthalene-2-carboxamides 3a-31.
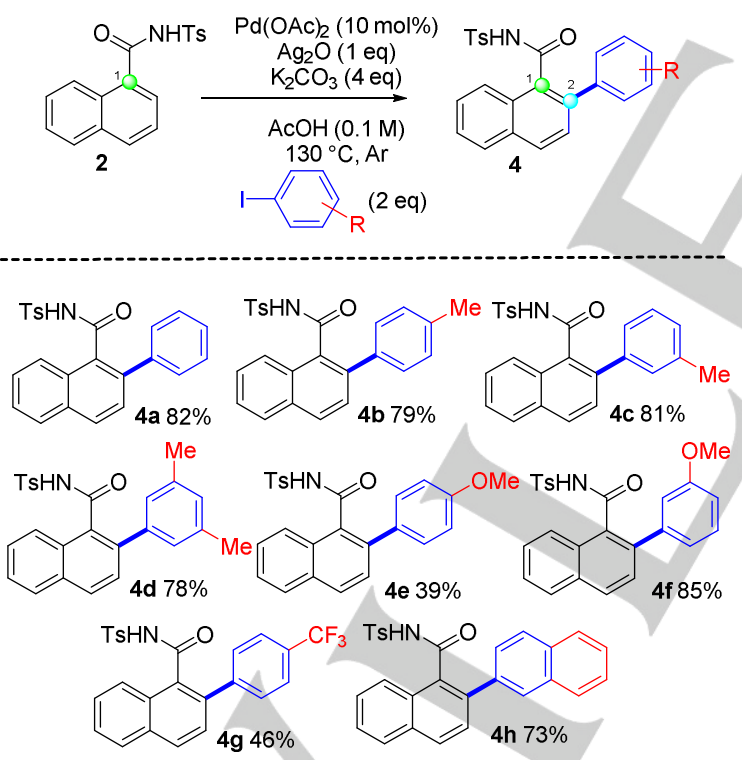

Scheme 2. Synthesis of 2-aryl- $N$-tosylnaphthalene-2-carboxamides $\mathbf{4 a - 4 h}$.

A similar trend was observed when naphthalene 2 was subjected to $\mathrm{C}-\mathrm{H}$ arylation process (scheme 2). Under the aforementioned reaction conditions, meta- and para-substituted arenes could be installed in high yields. Again, it was also possible to install a bulky naphthalene fragment in $73 \%$ yield.
Under our conditions, no bisarylated products in positions 2 and 8 of the naphthalene platform could be observed.

Our next goal was the construction of angular and linear tetra and pentacyclic fluorenones comprising one or two naphthalene motifs. The main point was to set best conditions to favour the electrophilic cyclisation avoiding cleavage of the directing group and degradation in acidic medium. Among the various conditions and acidic promoters explored (see ESI), the use of $\mathrm{TfOH}$ (12 eq) in $\mathrm{AcOH}(0.1 \mathrm{M})$ appeared suitable to efficiently promote the cyclization towards fluorenones 5 (scheme 3 ).
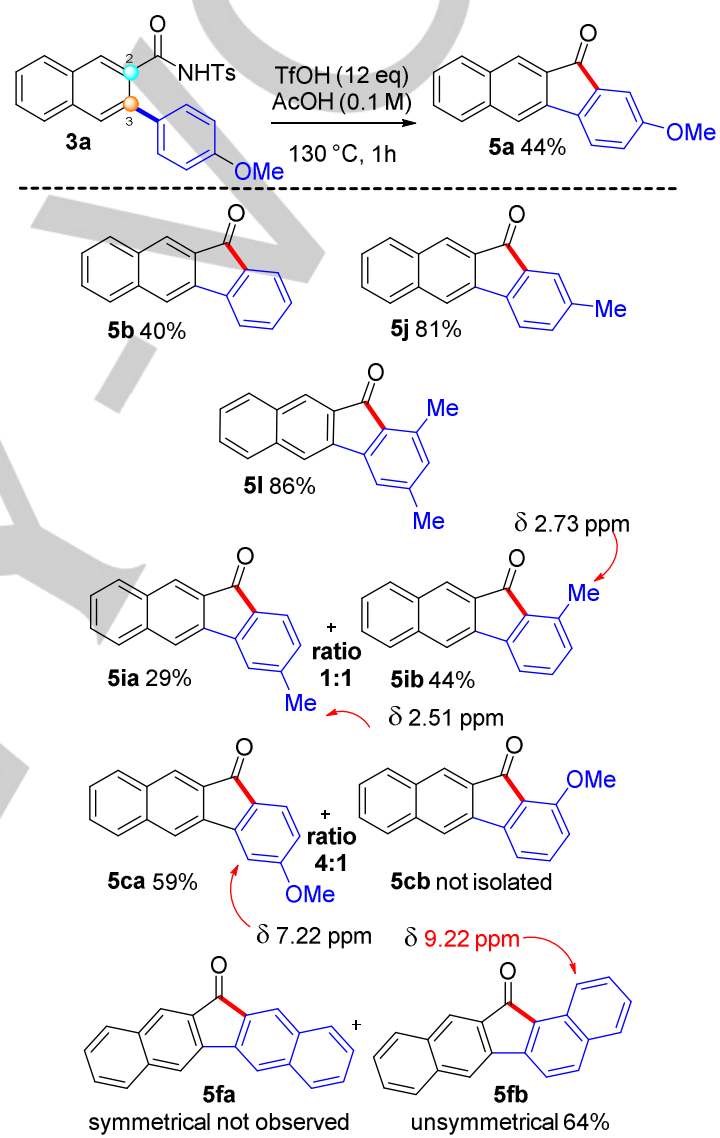

Scheme 3. Synthesis of fluorenones 5 . Ratio determined by ${ }^{1} \mathrm{H}$ NMR on crude material. Isolated yields.

Compounds $\mathbf{3} \mathbf{a}, \mathbf{3} \mathbf{b}, \mathbf{3} \mathbf{j}$ and $\mathbf{3} \mathbf{l}$ bearing symmetrical substitution pattern display one cyclization site. In all cases under the aforementioned cyclisation conditions, almost complete conversions were observed and the corresponding fluorenones were isolated in modest to high yields.

Naphthalenes $\mathbf{3 c}, \mathbf{3 f}$ and $\mathbf{3 i}$ were next subjected to cyclization under acidic conditions. These substrates display two potential cyclization sites due to the meta substitution pattern of the phenyl fragment installed at position 3 of the naphthalene platform. 3i bearing a meta methyl substituent afforded two separable regioisomers in a 1:1 ratio. Careful ${ }^{1} \mathrm{H}$ NMR analysis 
of the crude reaction mixture, showed distinct signals which account for two different methyl groups resonating at $2.51 \mathrm{ppm}$ and $2.73 \mathrm{ppm}$ respectively. Both fluorenones were isolated in $29 \%$ and $44 \%$ yield respectively.

The presence of the strongly electron-releasing methoxy group in precursor 3c also led to a mixture of regioisomers in a $4: 1$ ratio from which fluorenones $\mathbf{5}$ ca could be isolated in $59 \%$. Finally, $\mathbf{3 f}$ afforded the linear fluorenone $\mathbf{5} \mathbf{f b}$ as the sole cyclisation product in $64 \%$ isolated yield. In this case, the possible symmetrical fluorenone $\mathbf{5 f a}$ was not observed.

The regioselectivity of the cyclization of $\mathbf{3 c}, \mathbf{3 i}$ and $\mathbf{3} \mathbf{f}$ was studied by DFT calculations (B3LYP/6-31+g(d,p)) allowing comparison of the reaction paths leading to both possible isomers from the acylium cation intermediate (figure 2). In the case of $\mathbf{3} \mathbf{i}$ (methyl substituent) both paths leading to $\mathbf{5 i a}$ and $\mathbf{5 i b}$ have very close energy profiles (figure 2 up). For the methoxy substituent (3c, figure 2 middle), both activation energies are close but the product $5 \mathrm{ca}$ is more stable by $19.2 \mathrm{~kJ} / \mathrm{mol}$. Finally, from $\mathbf{3 f}$ (naphthyl, figure 2 down), the path leading to product $\mathbf{5 f b}$ has a lower activation barrier $(12.1 \mathrm{~kJ} / \mathrm{mol})$ than the one leading to $\mathbf{5 f a}$. Furthermore, the product $\mathbf{5 f b}$ is more stable than $\mathbf{5 f a}$ by $33.7 \mathrm{~kJ} / \mathrm{mol}$. Thus, the experimentally observed regioselectivities can be explained in terms of activation barrier differences and product stability: the equivalent reaction profiles observed from $3 \mathbf{i}$ accounts for the $5 \mathbf{i a} / 5 \mathbf{i b} 1: 1$ ratio and the $5 \mathbf{c a} / 5 \mathbf{c b} 4: 1$ ratio results from the higher stability of the former. ${ }^{[11]}$ Finally, 5 fa was not observed because of the very unfavourable energetic profile required for its formation compare to $\mathbf{5} \mathbf{f b}$.

Similar trends were observed when 2-aryl- $N$-tosylnaphthalene-1carboxamides 4 were subjected to the similar cyclisation conditions (figure 3 ). High yields of angular fluorenones have been obtained when the starting material was substituted by electron-releasing groups such as $\mathbf{6} \mathbf{b}$ and $\mathbf{6} \mathbf{d}$ for examples. As expected, moderate yield (24\%) was obtained when naphthalene $\mathbf{4 g}$ bearing a $\mathrm{CF}_{3}$ group was submitted to the cyclization process. Again, $6 \mathrm{ca}$ and $6 \mathrm{cb}$ whose arose from a cyclization at two different sites of the starting material $\mathbf{4 c}$ were isolated $47 \%$ and $34 \%$ yields respectively. Finally, $\mathbf{4 h}$ afforded the symmetrical fluorenone 6 ha in $21 \%$ isolated yield. In this case, the unsymmetrical fluorenone $6 \mathrm{hb}$ was not observed.

The regioselectivity of the cyclization of $\mathbf{4 c}$ and $\mathbf{4 h}$ was studied using the same in silico approach as for series $\mathbf{3}$ (see ESI for the corresponding energy profiles and reaction paths). In the case of 4c (methyl substituent) both reaction pathways leading to 6ca and $6 \mathbf{c b}$ have very close energy profiles. From $\mathbf{4 h}$, the path leading to product 6 ha has a lower activation barrier (12.4 $\mathrm{kJ} / \mathrm{mol}$ ) than the one leading to $6 \mathrm{hb}$ and the product $6 \mathrm{ha}$ is more stable than $6 \mathrm{hb}$ by $32.7 \mathrm{~kJ} / \mathrm{mol}$. As previously observed for the series of carboxamides 3 , the cyclisation regioselectivity of derivatives 4 can also be explained in terms of activation barrier differences and product stability: a $6 \mathbf{c a} / 6 \mathrm{cb} 1.6: 1$ ratio is caused by the equivalence of both pathway profiles; 6 ha is the only observed product because of the very favourable energetic profile for its formation compare to $\mathbf{6 h b}$. The regioselectivity observed for the cyclisation of $\mathbf{3}$ and $\mathbf{4}$ seems to be governed by electronic effects typical of the Friedel-Craft reaction and not by steric ones. Indeed, in the case of the tolyl substituent ( $\mathbf{3} \mathbf{i}$ and 4c) ortho and para positions are equally reactive while in the case of the methoxy substituent $(\mathbf{3 c})$ the para position is more reactive. Finally, in the naphthyl derivative (6ha), carbon 1 of the naphthalene group is favoured.

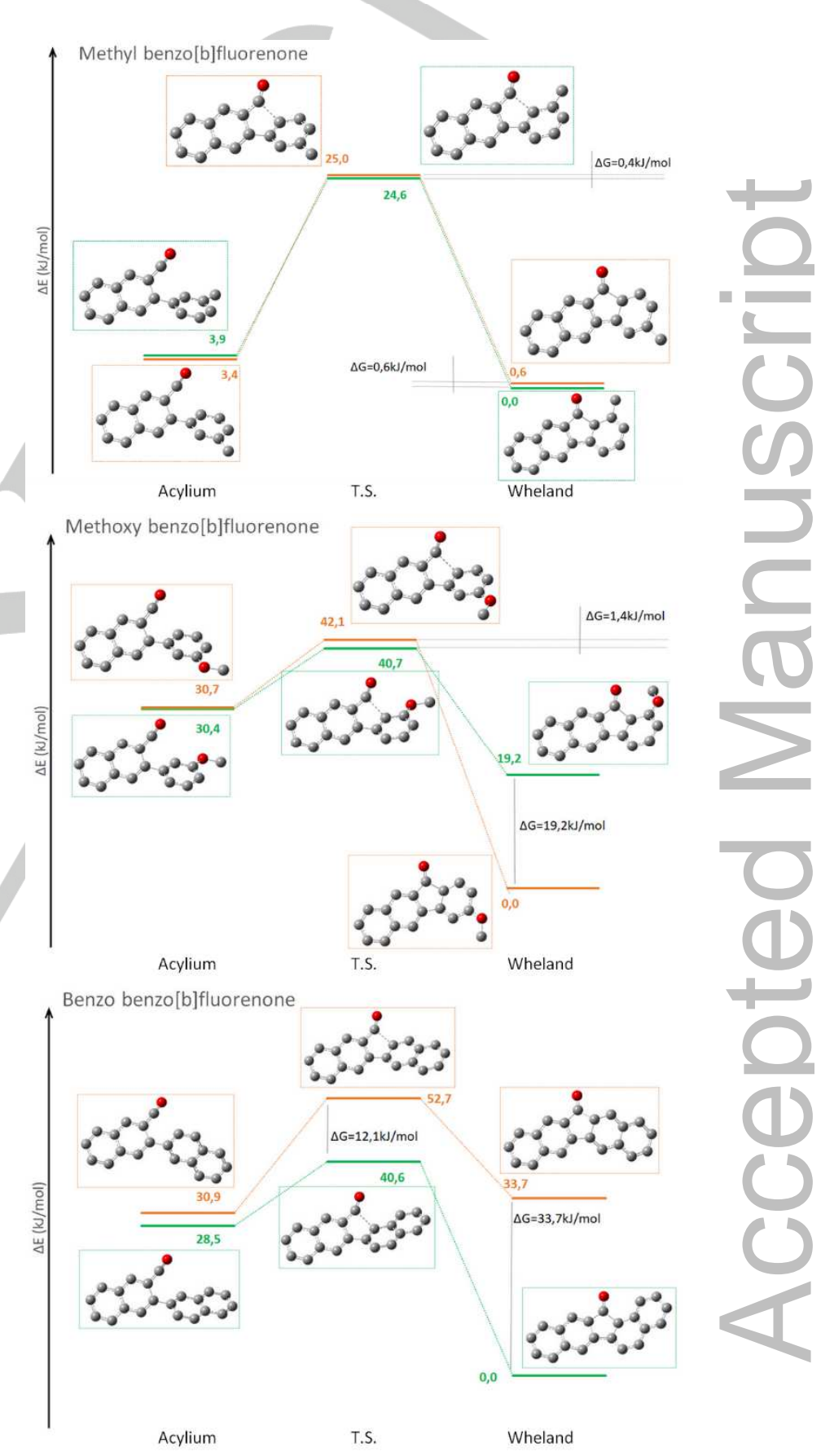

Figure 2. Energy profiles and reaction paths starting from acylium intermediates (5ia vs 5ib figure 2 up, $5 \mathrm{ca}$ vs $5 \mathrm{cb}$ figure 2 middle, $5 \mathrm{fa}$ vs $5 \mathrm{fb}$ figure 2 down). 


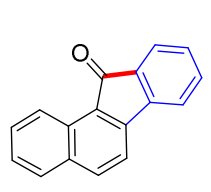

6a $83 \%$<smiles>Cc1cc(C)c2c(c1)-c1ccc3ccccc3c1C2=O</smiles><smiles>O=C1c2cc(C(F)(F)F)ccc2-c2ccc3ccccc3c21</smiles>

$6 \mathrm{~g} 24 \%$

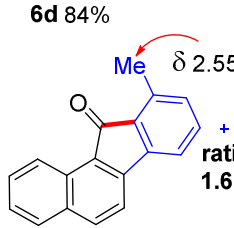

6ca $47 \%$<smiles>O=C1c2c(ccc3ccccc23)-c2ccc3ccccc3c21</smiles>

symmetrical $21 \%$ 6b $93 \%$

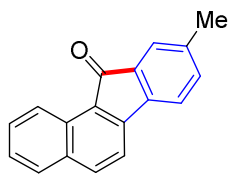

$\mathrm{CF}_{3}$

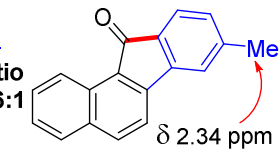

6 cb $34 \%$

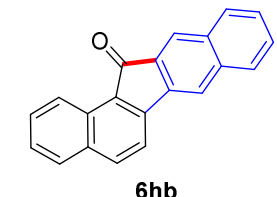

unsymmetrical not observed

Figure 3. Synthesis of fluorenones $6 a-6 e$ from naphthalenes 4 .

Finally, we also examined the possible transformation of compounds $\mathbf{3}$ and $\mathbf{4}$ towards angular and linear naphthalenebased phenanthridinones. Although such transformation has been reported within the benzene series, ${ }^{8 c, 8 d}$ the access to benzofused phenanthridinones from naphthalene substrates required to set precise reaction conditions and catalytic system (see ESI). Indeed, both the nature of solvent and the temperature have a significant effect on the reaction course. Only DMSO at $140{ }^{\circ} \mathrm{C}$ for $20 \mathrm{~h}$ was found effective for the obtention of target $7 \mathrm{a}$ in $65 \%$ yield (scheme 4). At lower temperature no reaction occurred even at $120^{\circ} \mathrm{C}$ 9h and in some cases higher temperatures led to degradation. Similarly, no reaction occurred when DCE, DMF, $\mathrm{AcOH}$ or $\mathrm{DMSO} / \mathrm{AcOH}$ mixtures were used as the solvent. Among the additives and conditions tested, $\mathrm{Cu}(\mathrm{OAc})_{2}$ under an $\mathrm{O}_{2}$ atmosphere revealed the only effective combination. In addition, only the use of $\mathrm{PdCl}_{2}$ afforded the expected phenanthridinones. As a consequence, $\mathrm{PdCl}_{2}, \mathrm{Cu}(\mathrm{OAc})_{2}$, in $\mathrm{DMSO}$ at $140^{\circ} \mathrm{C}$ under $\mathrm{O}_{2}$ atmosphere were used as the experimental conditions to prepare diversely substituted benzofused phenanthridinones.

The cyclisation reaction was next extended to substrates $\mathbf{3}$ and 4 (Scheme 4 and figure 4) and results obtained deserve some comments. The $\mathrm{Pd} / \mathrm{Cu}$-catalysed cyclisation was effective at $140{ }^{\circ} \mathrm{C}$ when the aryl group located in position 2 was substituted by electron-donating groups in para position.

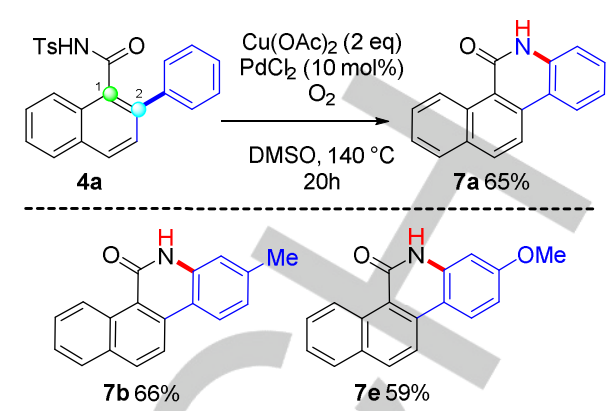

Scheme 4. Synthesis of naphthalene-based phenanthridinones 7 from naphthalenes 4 .

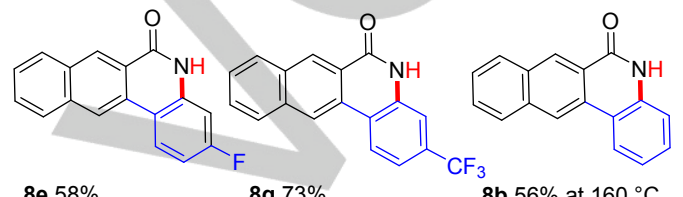

8 e $58 \%$ $8 \mathrm{~g} 73 \%$ no conversion at $140{ }^{\circ} \mathrm{C}$<smiles></smiles>
$\mathrm{O}$<smiles>[X]c1ccc2c3cc4ccccc4cc3c(=O)n([R])c2c1</smiles>

8j $52 \%$ at $160{ }^{\circ} \mathrm{C}$ as a mixture of $\mathrm{NH}$ and $\mathrm{NTs}$

Figure 4. Synthesis of phenanthridinones 8 from naphthalenes 3 .

Similarly, phenanthridinones $\mathbf{7 b}$ and 7 e were isolated in $59 \%$ to $66 \%$ yields. Noteworthy, both $\mathrm{C}-\mathrm{H}$ activation and $\mathrm{N}$-deprotection occurred under our conditions. Unfortunately, if aryls contain electron-withdrawing substituents $\left(\mathrm{CF}_{3}\right)$, naphthalene or even meta methoxy (3g, $\mathbf{3 f}, \mathbf{3 c}$ respectively), the formation of phenanthridinones fails. At $140{ }^{\circ} \mathrm{C}$ or $160{ }^{\circ} \mathrm{C}$, the latter starting materials were found unreacted in the crude reaction mixture. The outcome of the $\mathrm{Pd} / \mathrm{Cu}$-cyclisation seems to be strongly dependent of the substitution pattern of both the naphthalene platform and the aryl group. When the $N$-tosyl carboxamide group is located in position 2 of the naphthalene platform, cyclisation occurred fairly at $140{ }^{\circ} \mathrm{C}$ for aryl groups substituted by electron-withdrawing groups such as $8 \mathbf{e}$ and $\mathbf{8 g}$. In contrast, at $140{ }^{\circ} \mathrm{C}$, no conversion of the starting material bearing donating groups ( $p-\mathrm{MeO}$, or $m-\mathrm{MeO}$ ) was observed. Higher temperature $\left(160^{\circ} \mathrm{C}\right)$ was required to ensure cyclisation towards the phenanthridinone targets $\mathbf{8 a}, \mathbf{8 c}$ and $\mathbf{8 j}$ albeit in somewhat lesser yields ranging from $44 \%$ to $52 \%$ yields. Interestingly $8 \mathbf{j}$ was obtained as a mixture of $\mathrm{NH}$ and NTs products, indicating that cyclisation plausibly occurred at the early stage of the cyclisation prior to the cleavage of the N-Ts bond observed under the harsh reaction conditions used. Further, only one of two potential regioisomers was observed in the case of compound $\mathbf{8 c}$. Unfortunately, substrates $\mathbf{4 d}$ and $\mathbf{4 h}$ revealed reluctant to cyclisation, even at $160{ }^{\circ} \mathrm{C}$ affording only unidentified degradation products. The outcome of the $\mathrm{Pd} / \mathrm{Cu}$ - 
promoted cyclisation shows noticeable and intriguing difference of reactivity moving from precursors $\mathbf{3}$ to $\mathbf{4}$ but also switching from an electron donating to an electron withdrawing group. The reactivity and selectivity of the cyclisation was studied by NBO analysis and local electrophilicity/nucleophilicity on the reaction centres using Fukui function. Both approaches did not give any useful insight into the reaction outcome. At this stage further analysis of the reaction mechanism would be necessary but is out of the scope of this paper.

\section{Conclusions}

In summary, the selective $\mathrm{C}-\mathrm{H}$ arylation of naphthalenes bearing $\mathrm{N}$-tosyl carboxamides is described. The use of $\mathrm{Pd}(\mathrm{OAc})_{2}, \mathrm{Ag}_{2} \mathrm{O}$ as the catalytic combination allowed the selective installation of variously substituted aryl groups including naphthyl fragments at positions 2 and 3 of the naphthalene platforms. Twenty examples of new arylated naphthalenes bearing electron withdrawing and releasing groups were thus prepared. The choice of $N$-tosyl carboxamide as the directed group was also motivated by its synthetic flexibility as precursor of "CO" and "CO-NH" fragments. Indeed, $\mathrm{N}$-tosyl carboxamide group was proved to serve not only as efficient directing group but also as key precursors for the cyclopentanone and the $\delta$-lactam patterns of fluorenones and phenanthridinones respectively. Twenty-three examples of linear and angular polycyclic architectures illustrate this useful two step-economical procedure. The acid-mediated formation of the reactive acylium intermediate from the directing group followed by the electrophilic cyclisation accounts for the preparation of fluorenones backbones. Depending on the substitution pattern of the arylated naphthalene, we were able to transform such substrates into angular and linear tetra and pentacyclic fluorenones. DFT calculations fully confirmed the selectivity observed during the cyclisation step. Reaction pathways and crucial steps of the cyclisation processes were also determined. Further iterative $\mathrm{Pd} / \mathrm{Ag}$-catalysed $\mathrm{C}-\mathrm{H}$ arylation / $\mathrm{Pd} / \mathrm{Cu}$ catalysed $\mathrm{C}-\mathrm{H}$ activation sequence allowed the preparation of a new phenanthridinone derivatives. Our approach offers the prospect to build new extended and diversely substituted polycyclic architectures, thus widening the potential application domains of fluorenones and phenanthridinones. Application of our strategy using $\mathrm{N}$-tosyl carboxamides as dual directing group/key functional group precursor towards the preparation of other series of naphthalene-based architectures will be extended in a near future.

\section{Experimental Section}

Preparation of $\mathbf{N}$-tosyl-2-naphthamide 1. 2-naphtoic acid (5 g, 1 eq), $\mathrm{N}$-tosyl amine (1 eq), thionyl chloride (2.5 eq) and anhydrous $\mathrm{MgSO}_{4}$ (2 g) were solubilized in o-dichlorobenzene $(22 \mathrm{~mL})$ in an oven-dried round bottom flask filled with argon. The mixture was stirred for $24 \mathrm{~h}$ at $120^{\circ} \mathrm{C}$. The resulting mixture was quickly filtered off and the desired compound, which precipitate on cooling down to room temperature, was washed with hexanes, and used in the next step without further purification.
Preparation of $\mathbf{N}$-tosyl-1-napthamide 2. Under an atmosphere of argon, potassium carbonate $(2.5 \mathrm{eq})$ was added to a solution of $\mathrm{N}$-tosyl amine $(2.5 \mathrm{~g}, 1 \mathrm{eq})$ in dry THF $(20 \mathrm{~mL})$ in a round bottom flask and stirred for $1 \mathrm{~h}$ at $25^{\circ} \mathrm{C}$. Then a solution of 1 -naphthoyl chloride ( $\left.1.3 \mathrm{eq}\right)$ in dry THF (10 $\mathrm{mL}$ ) was added. The resulting mixture was stirred for $24 \mathrm{~h}$ at $85^{\circ} \mathrm{C}$. The residue was filtered through a pad of silica gel and the solvent was evaporated under reduced pressure and recrystallized in a mixture of ethyl acetate and hexane to give the expected product.

General procedure for the arylation of naphthamides. In a 2-dram screw glass tube flushed with argon, aryl iodide (2 eq) was added to a solution of $\mathrm{N}$-tosyl naphthyl amide (325.8 $\mathrm{mg}, 1 \mathrm{eq})$, silver oxide (1 eq), potassium carbonate ( $4 \mathrm{eq})$, and palladium acetate $(0.1 \mathrm{eq})$ in acetic acid $(10 \mathrm{~mL})$. The reaction mixture was stirred under argon for $24 \mathrm{~h}$ at $130^{\circ} \mathrm{C}$ and then filtered through a pad of celite. The residue was diluted in DCM, and washed with a saturated aqueous solution of $\mathrm{NaHCO}_{3}$, the organic layer was washed with a saturated aqueous solution of $\mathrm{NaCl}$, dried over $\mathrm{MgSO}_{4}$, concentrated and the product was purified by chromatography on silica gel (DCM/AcOEt, gradient from 100:0 to $90: 10$ ) to give the expected compound.

General procedure for the synthesis of benzofluorenones 5 and 6 . In a 2-dram screw glass tube, trifluoro methane sulfonic acid (12 eq) was added to a solution of aryl naphthyl amide (50 mg, 1 eq) in acetic acid $(1.2 \mathrm{~mL})$ and stirred for $1 \mathrm{~h}$ at $130{ }^{\circ} \mathrm{C}$. The reaction mixture was then cooled to room temperature, diluted in DCM, and carefully poured in aqueous saturated aqueous solution of $\mathrm{NaHCO}_{3}$, The organic layer was washed with a saturated aqueous solution of $\mathrm{NaCl}$, dried over $\mathrm{MgSO}_{4}$, concentrated and the product was purified by preparative TLC (DCM/hexanes 1:1) to give the expected compound.

General procedure for the synthesis of phenanthridinones 7 and 8 . A $10 \mathrm{~mL}$ screw glass tube was charged with arylated naphthamide $(0.1$ $\mathrm{mmol}, 1 \mathrm{eq}), \mathrm{Cu}(\mathrm{OAc})_{2}(2 \mathrm{eq})$ and $\mathrm{PdCl}_{2}(10 \mathrm{~mol} \%)$ in the presence of DMSO $(0.5 \mathrm{~mL}) . \mathrm{A} \mathrm{O}_{2}$ bubbling was injected to the solution before heating to $140{ }^{\circ} \mathrm{C}$ or $160{ }^{\circ} \mathrm{C}$ until disappearance of the starting material (generally $24 \mathrm{~h}$ ). The residue was then evaporated and the product was purified by chromatography on silica gel (cyclohexane/AcOEt, generally gradient from $7 / 3$ to $5 / 5$ ) to give the expected compound.

\section{Acknowledgments}

The Universities of Versailles St-Quentin and Paris-Sud, the French Ministry of Superior Education and Research (PhD fellowship BL), and the CNRS are gratefully acknowledged for their financial support. This work was also supported by the French National Research Agency under the program CHARMMMAT ANR-11-LABX-0039-grant.

Keywords: naphthalene $\bullet \mathrm{C}-\mathrm{H}$ arylation $\bullet$ fluorenone $\bullet$ palladium - phenanthridinone

[1] a) J. E. Anthony, Chem. Rev. 2006, 106, 5028. b) M. Bendikov, F Wudl, D. F. Perepichka, Chem. Rev. 2004, 104, 4891. c) M. Medarde, A. B. S. Maya, C. Pérez-Melero, J. Enzyme Inhib. Med. Chem. 2004, 19, 521. d) T. Ukita, Y. Nakamura, A. Kubo, Y. Yamamoto, M. Takahashi, J. Kotera, T. Ikeo, J. Med. Chem. 1999 42, 1293. e) C. Wang, H. Dong, W. Hu, Y. Liu, D. Zhu, Chem. Rev. 2012, 112, 2208. f) R. S. Ward, Nat. Prod. Rep. 1999, 16, 75. g) M. 
D. Watson, A. Fechtenkötter, K. Müllen, Chem. Rev. 2001, 101, 1267. h) Q. Ye, C. Chi, Chem. Mater. 2014, 26, 4046. i) Z. Zhao, Z. Wang, X. Zhang, S. Gao, X. Yang, Z. Duan, X. Gao, ChemPlusChem 2015, 80, 57.

a) L. Liang, X. Liu, Chem 2017, 2, 331. b) A. Ros, B. Estepa, P. Ramírez-López, E. Álvarez, R. Fernández, J. M. Lassaletta, J. Am. Chem. Soc. 2013, 135, 15730.

a) M. Gingras, Chem. Soc. Rev. 2013, 42, 968. b) A. C. Glass, S. Klonoski, L. N. Zakharov, S. Y. Liu, Chem. Commun. 2011, 47, 286. c) M. J. Narcis, N. Takenaka, Eur. J. Org. Chem. 2014, 2014, 21. d) G. Pieters, A. Gaucher, S. Marque, F. Maurel, P. Lesot, D. Prim, J. Org. Chem. 2010, 75, 2096. e) G. Pieters, A. Gaucher, J. Marrot, F. Maurel, J. V. Naubron, M. Jean, N. Vanthuyne, J. Crassous, D. Prim, Org. Lett. 2011, 13, 4450. f) G. Pieters, A. Gaucher, D. Prim, J. Marrot, Chem. Commun. 2009, 9, 4827. g) G. Pieters, K. Sbargoud, A. Bridoux, A. Gaucher, S. Marque, F. Bourdreux, J. Marrot, D. Flot, G. Wantz, O. Dautel, et al., Eur. J. Org. Chem. 2013, 2013, 490. h) Y. Shen, C. F. Chen, Chem. Rev. 2012, 112, 1463. a) E. Altinok, Z. C. Smith, S. W. Thomas, Macromolecules 2015, 48, 6825. b) K. M. Brummond, L. S. Kocsis, Acc. Chem. Res. 2015, 48, 2320. c) A. I. Guttentag, T. Wächter, K. K. Barr, J. M. Abendroth, T.B. Song, N. F. Sullivan, Y. Yang, D. L. Allara, M. Zharnikov, P. S. Weiss, J. Phys. Chem. C 2016, 120, 26736. d) F. Hayat, L. Kang, C. Y. Lee, D. Shin, Tetrahedron 2015, 71, 2945. e) C. Hetzer, D. M. Guldi, R. R. Tykwinski, Chem. - Eur. J. 2018, 24, 8245. f) H. Konishi, S. Futamata, X. Wang, K. Manabe, Adv. Synth. Catal. 2018, 360 , 1805. g) M. Li, L. Kou, L. Diao, Q. Zhang, Z. Li, Q. Wu, W. Lu, D. Pan, J. Phys. Chem. A 2015, 119, 3299. h) W. Yang, S. Wang, Q. Zhang, Q. Liu, X. Xu, Chem. Commun. 2015, 51, 661. a) C. Feng, T. Loh, J. Am. Chem. Soc. 2010, 17710. b) A. R. Katritzky, G. Zhang, L. Xie, J. Org. Chem. 1997, 62, 721. c) S. Ponra, M. R. Vitale, V. Michelet, V. Ratovelomanana-Vidal, J. Org. Chem. 2015, 80, 3250. d) K. Sakthivel, K. Srinivasan, J. Org. Chem. 2014, 79, 3244. e) S. Suzuki, K. Itami, J. Yamaguchi, Angew. Chem. Int. Ed. 2017, 56, 15010. f) H. Xu, S. Li, H. Liu, H. Fu, Y. Jiang, Chem. Commun. 2010, 46, 7617. g) S. Zhu, Y. Xiao, Z. Guo, H. Jiang, Org. Lett. 2013, 15, 898. a) Y. Aihara, N. Chatani, Chem. Sci. 2013, 4, 664. b) Y. Aihara, J. Wuelbern, N. Chatani, Bull. Chem. Soc. Jpn. 2015, 88, 438. c) R. K. Chinnagolla, M. Jeganmohan, Org. Lett. 2012, 14, 5246. d) Q. Gu, H. H. Al Mamari, K. Graczyk, E. Diers, L. Ackermann, Angew. Chem. Int. Ed. 2014, 53, 3868. e) L. Hu, Q. Gui, X. Chen, Z. Tan, G. Zhu, Org. Biomol. Chem. 2016, 14, 11070. f) J. Jiang, W. M. Zhang, J. J. Dai, J. Xu, H. J. Xu, J. Org. Chem. 2017, 82, 3622. g) J. Li, L. Ackermann, Chem. - Eur. J. 2015, 21, 5718. h) A. Mandal, J. Selvakumar, S. Dana, U. Mukherjee, M. Baidya, Chem. - Eur. J. 2018, 24, 3448. i) L. C. Misal Castro, N. Chatani, Chem. - Eur. J.
2014, 20, 4548. j) P. Nareddy, F. Jordan, S. E. Brenner-Moyer, M. Szostak, ACS Catal. 2016, 6, 4755. k) P. Nareddy, F. Jordan, M. Szostak, Chem. Sci. 2017, 8, 3204. I) D. Santrač, S. Cella, W. Wang, L. Ackermann, Eur. J. Org. Chem. 2016, 2016, 5429. m) Y. Shen, W. C. Cindy Lee, D. A. Gutierrez, J. J. Li, J. Org. Chem. 2017, 82, 11620. n) Y. Shi, L. Zhang, J. Lan, M. Zhang, F. Zhou, W. Wei, J. You, Angew. Chem. Int. Ed. 2018, 57, 9108. o) S. L. Yedage, B. M. Bhanage, J. Org. Chem. 2016, 81, 4103. p) S. Zhao, B. Liu, B. B. Zhan, W. D. Zhang, B. F. Shi, Org. Lett. 2016, 18, 4586.

[7] a) S. Castro, J. J. Fernández, R. Vicente, F. J. Fañanás, F. Rodríguez, Chem. Commun. 2012, 48, 9089. b) A. J. Hickman, M. S. Sanford, ACS Catal. 2011, 1, 170. c) O. Kobayashi, D. Uraguchi, T. Yamakawa, Org. Lett. 2009, 11, 2679. d) R. Li, L. Jiang, W. Lu, Organometallics 2006, 25, 5973. e) H. Liu, B. Yin, Z. Gao, Y. Li, H. Jiang, Chem. Commun. 2012, 48, 2033. f) J. Wencel-Delord, T. Dröge, F. Liu, F. Glorius, Chem. Soc. Rev. 2011, 40, 4740.

[8] a) A. Bechtoldt, C. Tirler, K. Raghuvanshi, S. Warratz, C. Kornhaaß, L. Ackermann, Angew. Chem. Int. Ed. 2016, 55, 264. b) F. Péron, C. Fossey, T. Cailly, F. Fabis, Org. Lett. 2012, 14, 1827. c) F. Péron, C. Fossey, J. Sopkova-Deoliveirasantos, T. Cailly, F. Fabis, Chem. Eur. J. 2014, 20, 7507. d) C. Zhu, J. R. Falck, Org. Lett. 2011, 13, 1214. e) C. Zhu, J. R. Falck, Chem. Commun. 2012, 48, 1674. f) C. Zhu, J. R. Falck, Tetrahedron 2012, 68, 9192.

[9] a) R. K. Chinnagolla, M. Jeganmohan, Org. Lett. 2012, 14, 5246. b) M. Feng, B. Tang, H. X. Xu, X. Jiang, Org. Lett. 2016, 18, 4352. c) T. Furuta, Y. Kitamura, A. Hashimoto, S. Fujii, K. Tanaka, T. Kan, Org. Lett. 2007, 9, 183. d) K. Inamoto, T. Saito, K. Hiroya, T. Doi, J. Org. Chem. 2010, 75, 3900. e) X. Li, J. Pan, S. Song, N. Jiao, Chem. Sci. 2016, 7, 5384. f) K. Luo, T. Cao, H. Jiang, L. Chen, S. Zhu, Org. Lett. 2017, 19, 5856. g) V. Rajeshkumar, T. H. Lee, S. C. Chuang, Org. Lett. 2013, 15, 1468. h) S. Sarkar, M. Jana, T. Narender, Eur. J. Org. Chem. 2013, 6491. i) D. Sun, B. Li, J. Lan, Q. Huang, J. You, Chem. Commun. 2016, 52, 3635. j) A. Vignesh, W. Kaminsky, N. Dharmaraj, ChemCatChem 2016, 8, 3207. k) X. Zhang, X. Ji, R. Su, B. L. Weeks, Z. Zhang, S. Deng, ChemPlusChem 2013, 78, 703. I) J. Zhao, D. Yue, M. A. Campo, R. C. Larock, J. Am. Chem. Soc. 2007, 129, 5288. m) Y. Bin Zhao, B. Mariampillai, D. A. Candito, B. Laleu, M. Li, M. Lautens, Angew. Chem. Int. Ed. 2009, 48, 1849.

[10] N. Gigant, J. E. Bäckvall, Org. Lett. 2014, 16, 4432.

[11] Our own theoretical and experimental results are in full accordance with a possible thermodynamic control as recently stated in the fluorenones series. See T. Mala'Bi, S. Pogodin, S. Cohen, I. Agranat, RSC Adv. 2013, 3, 21797. 
Entry for the Table of Contents (Please choose one layout)

Layout 1:

\section{FULL PAPER}

Dedicated to naphthalene derivatives. The Pd-catalysed $\mathrm{C}-\mathrm{H}$ arylation of naphthalene platforms is illustrated along with the dual role of the $\mathrm{N}$-tosyl carboxamides group. Our approach results in an improved access to linear and angular extended fluorenone and phenanthridinone architectures

*one or two words that highlight the emphasis of the paper or the field of the study

\section{C-H activation of naphthalene}

Benjamin Large, Nicolas Gigant,

Delphine Joseph*, Gilles Clavier and Damien Prim*

Page No. - Page No.

Site-selective arylation of naphthalenes: a key entry towards extended fluorenones and phenanthridinones 